\title{
Colorectal cancer liver metastases: laparoscopic and open radiofrequency-assisted surgery
}

Petr Vavra ${ }^{1-4}$, Jana Nowakova ${ }^{2}$, Petr Ostruszka ${ }^{1}$, Martin Hasal $^{2}$, Jana Jurcikova ${ }^{1}$, Lubomir Martinek ${ }^{1}$, Marek Penhaker ${ }^{2}$, Peter Ihnat ${ }^{1,4}$, Nagy Habib ${ }^{3}$, Pavel Zonca ${ }^{1,4}$

${ }^{1}$ University Hospital Ostrava, Ostrava, Czech Republic

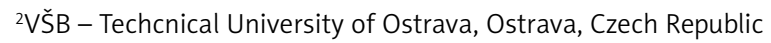

${ }^{3}$ Imperial College London, London, United Kingdom

${ }^{4}$ University of Ostrava, Ostrava, Czech Republic

Videosurgery Miniinv 2015; 10 (2): 205-212

DOI: 10.5114/wiitm.2015.52082

\begin{abstract}
Introduction: The liver is the most common site of colorectal metastases (colorectal liver metastases - CLM). Surgical treatment in combination with oncological therapy is the only potentially curative method. Unfortunately, only 10-25\% of patients are suitable for surgery. Traditionally, open liver resection (OLR) is usually performed. However, laparoscopic liver resection (LLR) has become popular worldwide in the last two decades.

Aim: To evaluate the effectiveness and benefits of radiofrequency minor LLR of CLM in comparison with OLR.

Material and methods: The indication for surgery was CLM and the possibility to perform minor laparoscopic or OLR not exceeding two hepatic segments according to Couinaud's classification.

Results: Sixty-six minor liver resections for CLM were performed. Twenty-five (37.9\%) patients underwent a laparoscopic approach and 41 (62.1\%) patients underwent OLR. The mean operative time was 166.4 min for LLR and $166.8 \mathrm{~min}$ for OLR. Average blood loss was $132.3 \pm 218.0 \mathrm{ml}$ during LLR and $149.5 \pm 277.5 \mathrm{ml}$ during OLR. Length of hospital stay was $8.4 \pm 2.0$ days for LLR and $10.5 \pm 5.8$ days for OLR. All resections were RO. There was no case of mortality. Postoperative complications were recognized in 9 (13.6\%) patients: 8 in the group of OLR patients and 1 in the LLR group. The median survival time for LLR was 70.5 months and for OLR 61.9 months. The 5-year overall survival rate was higher for $L L R$ vs. OLR - 82.1\% vs. 69.8\%. The average length of disease-free interval after LLR was greater (52.2 months) in comparison with OLR (49.4\%). The 5-year disease-free interval was $63.2 \%$ for LLR and $58 \%$ for OLR. Conclusions: Outcomes and oncological radicality of minor laparoscopic liver resections of CLM are comparable to outcomes of OLR.
\end{abstract}

Key words: colorectal cancer, liver metastases, laparoscopic liver resection, radiofrequency.

\section{Introduction}

The liver is the most common site of colorectal cancer metastases. Approximately $20 \%$ of patients suffering from colorectal cancer have liver metastases at the time of diagnosis; the other $30-40 \%$ of patients will develop them in the following postoperative period [1]. The median survival in patients with untreated colorectal cancer is in the range of 6-9 months, and 5-year survival is rather rare, ranging from 0 to $3 \%$ [2-4]. It is still true that surgical treatment in combination with oncological therapy

\section{Address for correspondence}

Martin Hasal MSc, VŠB - Technical University of Ostrava, 17. listopadu 15/2172, 70833 Ostrava - Poruba, Czech Republic,

phone: +420 720519 559, fax: +420 596918 507, e-mail: martin.hasal@vsb.cz 
is the only potentially curative treatment modality. The result is 5 -year survival of $16-74 \%$ and 10 -year survival of $9-69 \%$ in patients after $\mathrm{RO}$ resection [5]. Unfortunately, only 10-25\% of patients meet the criteria for implementation of RO surgical resection at the time of diagnosis [6].

\section{Aim}

The aim of this prospective study was to evaluate the effectiveness and benefits of radiofrequency minor laparoscopic liver resection (LLR) in the treatment of colorectal liver metastases (CLM). Minor laparoscopic resection was determined as a resection not exceeding more than 2 segments according to Couinaud's classification. The hypothesis of the study was that LLR can be compared with open liver resection (OLR) and statistically does not differ in the following monitored parameters: operating time, intraoperative blood loss, postoperative days spent in the intensive care unit (ICU) and hospital stay, amount of drainage in the first 2 days, duration to abdominal drain removal, postoperative complications, overall survival and disease-free interval.

\section{Material and methods}

Sixty-six patients with CLM not exceeding two hepatic segments were included in the study. Inclusion criteria were as follows: age over 18 years and the possibility to perform laparoscopic or open liver resection not exceeding two hepatic segments.

Exclusion criteria were as follows: technically unresectable hepatic lesions, hepatic lesions exceeding more than 2 segments, extrahepatic dissemination, metastasis of non-colorectal origin and patient unfit for surgery (ASA IV or more).

All eligible patients underwent a preoperative interview with the operating surgeon, physical examination, basic laboratory tests, carcinoembryonic antigen (CEA) determination, spiral computed tomography (CT) or magnetic resonance imaging (MRI) of the abdomen to assess the metastatic process accurately, chest X-ray, and anaesthetic preoperative examination. The minor laparoscopic procedures ranged from a simple local metastasectomy (wedge resection) through segmentectomy to bisegmentectomy. Postoperatively, patients were followed at the outpatient department.

Data were analysed using the MySQL database version 5 January 32 (Oracle, Redwood Shore, CA,
USA), SPSS statistical software version 18 (IBM, Rochester, MN, USA) and Statgraphics Centurion XV. Then Microsoft Excel 2007 (Microsoft, Redmond, WA, USA) and computer applet IO_binom.xlsx were used.

\section{Statistical analysis}

Descriptive statistics were used to determine the basic characteristics of the sample. The chi-square test $\left(\chi^{2}\right)$ was used to determine whether the data were distributed normally. The Mann-Whitney test was used to test differences between single groups (normal distribution was not observed). Kaplan-Meier curves (log rank, Breslow and Tarone-Ware tests) were used to determine differences in overall survival and identification of disease-free interval. The level of significance of 0.05 was set for all tests [7].

\section{Results}

A laparoscopic operation was performed in 25 (37.9\%) patients, and 41 (62.1\%) patients underwent conventional open surgery. Mean operative time was $166.4 \mathrm{~min}$ (50-370 $\mathrm{min}$ ) for LLR and 166.8 min (80-335 $\mathrm{min}$ ) for OLR. Blood loss during surgery was $132.3 \pm 218 \mathrm{ml}$ after LLR and $149.5 \pm 277.5 \mathrm{ml}$ after OLR. Number of days of hospitalization in the ICU was $3.0 \pm 1.9$ days ( $0-7$ days) for LLR and $3.4 \pm 1.8$ days (0-7) for OLR. Length of hospital stay was 8.4 \pm 2 days for LLR and $10.5 \pm 5.8$ days for OLR. Secretion from the abdominal drain on the first postoperative day was $82.5 \pm 116.2 \mathrm{ml}$ after LLR and $47.2 \pm 63.3$ $\mathrm{ml}$ after OLR. The abdominal drain was removed 4.7 \pm 1.9 days after LLR and $6.2 \pm 6.1$ days after OLR.

Statistical evaluation has shown that there was not a statistically significant difference between LLR and OLR in terms of the operation time, perioperative blood loss, number of days in the postoperative ICU, length of stay in hospital (Table I), the amount of secretion from the abdominal drain or the average number of days to abdominal drain removal.

Postoperative complications occurred in 9 (13.6\%) patients. There were 8 (19.5\%) complications (pneumonia, wound infection, respiratory failure, bile leak [2x], hematoma, liver abscess, urinary infection) in the group of patients undergoing OLR and only 1 (4\%) (wound infection) in the group of patients undergoing LLR. This difference in postoperative complications was statistically significant $(p=0.038)$.

The average survival time for LLR was 70.5 months and for OLR was 61.9 months. The 5-year 
Table I. Comparison of the monitored parameters in LLR and OLR groups of patients

\begin{tabular}{|c|c|c|c|c|c|c|c|c|c|c|}
\hline \multirow[t]{3}{*}{ Parameter } & \multicolumn{2}{|c|}{ Age [years] } & \multicolumn{2}{|c|}{$\begin{array}{l}\text { Operative time } \\
\text { [min] }\end{array}$} & \multicolumn{2}{|c|}{ Blood loss [ml] } & \multicolumn{2}{|c|}{$\begin{array}{l}\text { Length of stay in } \\
\text { intensive care unit } \\
\text { [days] }\end{array}$} & \multicolumn{2}{|c|}{$\begin{array}{l}\text { Length of stay in } \\
\text { hospital [days] }\end{array}$} \\
\hline & \multicolumn{10}{|c|}{ Type of operative approach } \\
\hline & LLR & OLR & LLR & OLR & LLR & OLR & LLR & OLR & LLR & OLR \\
\hline Mean & 62.1 & 61.3 & 166.4 & 166.8 & 132.3 & 149.5 & 3 & 3.4 & 8.4 & 10.5 \\
\hline Median & 63 & 64 & 171 & 160 & 50 & 57.5 & 2 & 4 & 8 & 8 \\
\hline $\begin{array}{l}\text { Standard } \\
\text { deviation }\end{array}$ & 10.3 & 9.7 & 81.5 & 59 & 218 & 277.5 & 1.9 & 1.8 & 2 & 5.8 \\
\hline Sig. & \multicolumn{2}{|c|}{$\mathrm{NS}, p=0.381$} & \multicolumn{2}{|c|}{$\mathrm{NS}, p=0.492$} & \multicolumn{2}{|c|}{ NS, $p=0.422$} & \multicolumn{2}{|c|}{ NS, $p=0.136$} & \multicolumn{2}{|c|}{ NS, $p=0.291$} \\
\hline
\end{tabular}

Table II. Summary for survival time based on the type of surgery. Values of $p$ for the individual tests in the assessment of the statistical difference in survival

\begin{tabular}{|c|c|c|c|c|c|}
\hline \multirow[t]{2}{*}{ Operative approach } & \multirow{2}{*}{$\begin{array}{l}\text { Mean survival time } \\
\text { [months] }\end{array}$} & \multirow[t]{2}{*}{ 5-year survival (\%) } & \multicolumn{3}{|c|}{ Test $p$-value } \\
\hline & & & Log rank & Breslow & Tarone-Ware \\
\hline Laparoscopic & 70.5 & 82.1 & 0.398 & 0.413 & 0.402 \\
\hline Open & 61.9 & 69.8 & & & \\
\hline
\end{tabular}

overall survival rate was higher for LLR versus OLR $-82.1 \%$ vs. $69.8 \%$ (Table II, Figure 1). Based on log rank, Breslow and Tarone-Ware tests, no statistically significant difference was found. According to the tests, there was no difference in the overall survival of patients with CLM depending on the type of surgery - LLR or OLR.

The average length of disease-free interval for LLR was greater (52.2 months) in comparison with OLR (49.4 months). The 5-year disease-free interval was for LLR 63.2\% and for OLR 58.0\% (Table III, Figure 2). Statistical evaluation revealed no difference in disease-free interval in patients with CLM depending on the operative approach - laparoscopic or open.

\section{Discussion}

In 1993, Gagner et al. [8] performed the first laparoscopic liver resection. The following two decades meant rapid development of laparoscopy [9]. Nowadays, the number and rate of laparoscopic liver procedures are still increasing. Generally, the proportion of laparoscopic procedures in liver surgery is reported between 5\% and 30\% [10-13]. In several major world centres the proportion of laparoscopic procedures is higher - around 50-80\% [14-17].

In 2011, Nguen et al. [18] reported his experience with a total of 1294 patients. Three hundred and fourteen $(24.3 \%)$ of them were operated on laparo-

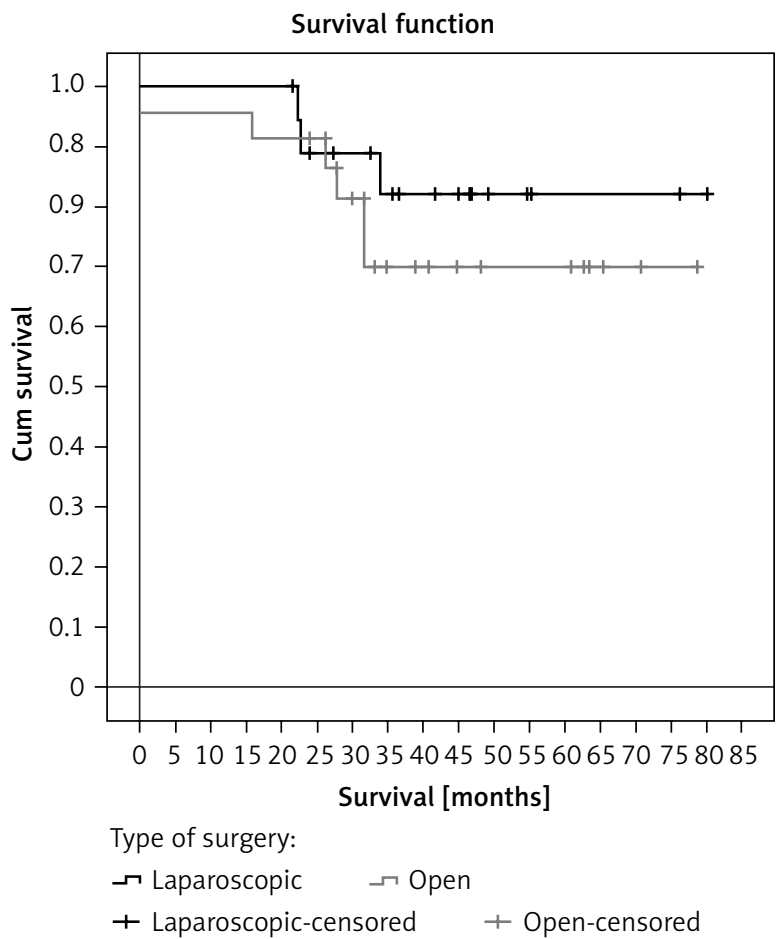

Figure 1. Kaplan-Meier survival curves for patients with CLM and RO resections according to operative approach

scopically. Han et al. [19] reported 386 liver resections in their statistical evaluation within 5 years; 170 (44\%) were performed laparoscopically. In this 
Table III. Summary for disease-free interval based on type of surgery. Values of $p$ for the individual tests in the assessment of the statistical difference in survival

\begin{tabular}{|c|c|c|c|c|c|}
\hline \multirow[t]{2}{*}{ Operative approach } & \multirow{2}{*}{$\begin{array}{c}\text { Mean disease-free } \\
\text { interval [months] }\end{array}$} & \multirow{2}{*}{$\begin{array}{l}\text { 5-year disease-free } \\
\text { interval (\%) }\end{array}$} & \multicolumn{3}{|c|}{ Test $p$-value } \\
\hline & & & Log rank & Breslow & Tarone-Ware \\
\hline Laparoscopic & 52.2 & 63.2 & 0.674 & 0.570 & 0.624 \\
\hline Open & 49.4 & 58.0 & & & \\
\hline
\end{tabular}

study conducted at the University Hospital Ostrava, the proportion of LLR was $35.9 \%$. This is a fairly significant proportion, which is determined by the historical focus on minimally invasive procedures and the possibility of using advanced laparoscopic techniques [20, 21].

Indication criteria for the application of LLR are not clearly established. It depends particularly on the size and location of metastases. It is also necessary to take into account previous surgery, patient's condition and comorbidities, surgeon's experience and workplace customs. Generally, smaller metastases located in the anterolateral segments S2-6 are considered optimal for the laparoscopic approach. Conversely, metastases bigger than $6 \mathrm{~cm}$, their penetration into surrounding structures or location near

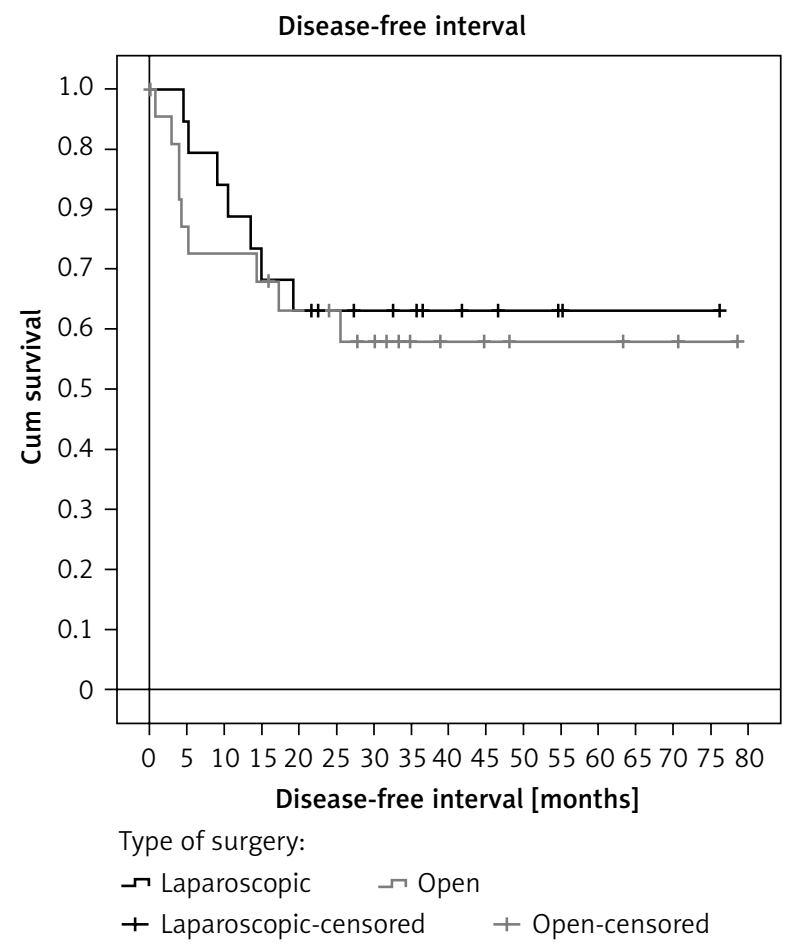

Figure 2. Kaplan-Meier disease-free curves for patients with CLM and RO resections according to operative approach the hepatic hilum, vena cava or in postero-superior segments S1, S4a, S7 and S8 are considered inappropriate for laparoscopy [22, 23]. However, Cho et al. reported a series of 36 patients with lesions in the postero-superior segment (S7, 8, 4a and 1) treated only with the laparoscopic approach [17, 24]. The role of laparoscopy for tumours requiring resection of postero-superior segments should be sufficiently specified in the future.

The number of patients in published studies varies widely. There are studies with a small number of patients [25-28]. On the other hand, there are studies with a much larger group of patients - Nguyen et al. evaluated 314 patients [18], Koffron et al. 300 patients [16]. In 2007 Simillis et al. [29] published the results of a meta-analysis comparing LLR with OLR. In the group of patients studied at the University Hospital Ostrava, there were 66 patients with CLM, and 25 patients were operated on laparoscopically. The number of patients is comparable with the middle of the spectrum in individual studies in the world literature.

Length of hospital stay in our study was $8.4 \pm 2$ days after LLR and $10.5 \pm 5.8$ days after OLR. In comparison of laparoscopic and open liver resection, there was no significant difference in favour of laparoscopic surgery. Our length of hospital stay is the average length of hospital stay after laparoscopic resections reported in studies from Europe, which ranges between 3.5 and 10 days [27, 30-42]. The average length of hospital stay differed greatly among individual studies. As regards the duration of hospital stay after liver resection, there is a very interesting comparison of local customs and traditions. Studies published in the USA $[14,16,43,44]$ indicate an average length of hospital stay of 1.9-4 days after LLR, while above-mentioned European studies report 3.510 days. Studies published in Asia indicate the length of hospital stay much longer, between 4 and 20 days [45-52]. However, the trend was consistent regardless of continents and pointed to a shorter length of hospital stay in the group of LLR compared to OLR. It 
should be noted that although the length of hospital stay was in our study shorter after laparoscopic operations, the results in favour of laparoscopy were not statistically significant.

The average number of days of hospitalization in the ICU in our study was 3.0 days for LLR and 3.4 days for OLR. Statistical evaluation found no difference. Abu Hilal et al. compared the results of right-sided hemihepatectomy performed laparoscopically (36 patients) and openly (34 patients). He compared the duration of hospitalization in an ICU, where the median was 2 days vs. 4 days $(p<0.0001)$ and the total hospitalization period ( 5 days vs. 9 days, $p<0.0001$ ) was significantly shorter in the group of patients treated laparoscopically [53].

At the beginning of laparoscopic resection, significantly longer operating time was stated as one of the main disadvantages in comparison with open resection [39, 42, 43]. The development of laparoscopy and surgical techniques compensated this difference gradually. In our study, similarly to many other studies [15, 27, 30, 35], a significant difference in operating time was not found. On the other hand, there are studies proving shorter operating time of the laparoscopic approach $[14,16,32]$. These differences may be caused by the method of liver transection, with authors using the harmonic scalpel reporting a longer operating time, while authors using endostaplers reported a shorter operating time.

Laparoscopy is considered to be a miniinvasive and gentle method. Most studies show significantly lower intraoperative blood loss compared to the open approach [11, 14, 30, 43, 48, 54]. In our study significant differences between blood loss during laparoscopic surgery compared to losses in open procedures ( $p=0.422$ ) were not found. Generally, it is considered that blood loss should be smaller in the laparoscopic approach because of better visualization of the operative field, careful dissection by laparoscopic instruments, established pneumoperitoneum and reduced blood loss through laparoscopic wounds [55].

Monitoring of postoperative morbidity and mortality is one of the main indicators of the effect of laparoscopic treatment. While many studies have shown a comparable amount of postoperative complications between LLR and OLR, there are also studies $[11,27,32,34,35,44,54]$ showing a significantly lower incidence of complications after laparoscopic operations (6-13.8\%) compared to the number of complications after open procedures $(28.9 \%$ to
47.8\%). There were no differences in perioperative mortality between the two groups of patients in these trials. Our study belongs to the category of studies with lower postoperative morbidity (4.0\%) during laparoscopic operations (compared to patients operated openly $19.5 \%$ ). The relatively favourable outcome of complications after laparoscopic resection is fully consistent with the results of other authors in the world literature in recent years [56]. Lee et al. reported a $4 \%$ complication rate in laparoscopic resection [48], Shimada et al. [49] 5.9\%, Rowe et al. [54] and Rau et al. [40] 6\%, Topal et al. $8 \%$ [11]. These results demonstrate significant progress in the development of technology and operational skills of surgeons. Mizuguchi et al. [57] found postoperative morbidity to be significantly lower in patients operated on laparoscopically, ranging from $5.9 \%(47)$ to $34.2 \%$ [42], while in OLR it ranged from $6.7 \%$ [33] to $47.8 \%$ [34].

The key question is oncological radicality after laparoscopic surgery. Careful intraoperative manipulation, no-touch technique, the use of plastic bags to remove material from the abdominal cavity and others lead to prevention of port-site metastases [55]. Comparison of overall survival curves and disease-free interval is crucial. Many studies have found no significant difference in 3- and 5-year survival interval depending on the chosen approach (Table IV) [18]. Cai et al. reported survival of patients with HCC after laparoscopic resection as 95.4\%, 67.5\% and $56.2 \%$ after 1,3 and 5 years, while survival was $100 \%, 73.8 \%$ and $53.8 \%$ after open resection [45]. Ito et al. found no significant difference in 3-year survival in patients with CLM operated on by an open or laparoscopic approach [43].

Five-year survival interval in our study was statistically evaluated using Kaplan-Meier curves. The 5 -year survival rate for minor RO resection for CLM was $82.1 \%$ for operations performed laparoscopically and $69.8 \%$ for operations performed openly. A statistical evaluation showed that there was no difference in survival interval depending on the selected operation - open or laparoscopic. Oncological radicality of laparoscopic surgery for CLM in our group of patients was comparable with the radicality of operations performed conventionally openly.

\section{Conclusions}

Our study showed that minor LLR of CLM was comparable with outcomes of procedures performed 
Table IV. Overall survival after LLR vs. OLR for cancer in comparative studies

\begin{tabular}{|c|c|c|c|c|c|c|}
\hline \multirow[t]{2}{*}{ Source, year } & \multirow[t]{2}{*}{ Country } & \multirow[t]{2}{*}{ Tumour } & \multicolumn{2}{|c|}{ Overall survival [\%] } & \multirow[t]{2}{*}{ Follow-up [years] } & \multirow[t]{2}{*}{ Value of $p$} \\
\hline & & & LLR & OLR & & \\
\hline Kaneko et al., 2005 [28] & Japan & $\mathrm{HCC}$ & 61 & 62 & 5 & NS \\
\hline Cai et al., 2008 [45] & China & Mix & 50 & 51 & 5 & NS \\
\hline Belli et al., 2009 [32] & Italy & $\mathrm{HCC}$ & 67 & 61 & 3 & NS \\
\hline Ito et al., 2009 [43] & US & CLM & 72 & 56 & 3 & NS \\
\hline Lai et al., 2009 [47] & $\begin{array}{l}\text { Hong } \\
\text { Kong }\end{array}$ & $\mathrm{HCC}$ & 60 & 60 & 3 & NS \\
\hline Castaing et al., 2009 [31] & France & CLM & 64 & 56 & 5 & NS \\
\hline Endo et al., 2009 [50] & Japan & $\mathrm{HCC}$ & 57 & 48 & 5 & NS \\
\hline Sarpel et al., 2009 [58] & US & $\mathrm{HCC}$ & 95 & 75 & 5 & NS \\
\hline Tranchart et al., 2010 [30] & France & $\mathrm{HCC}$ & 46 & 37 & 5 & NS \\
\hline Vavra et al., 2014 & Czech & CLM & 82 & 70 & 5 & NS \\
\hline
\end{tabular}

openly. The oncological radicality of the laparoscopic approach for CLM not exceeding two hepatic segments was comparable with the conventional open surgery.

The indication for LLR does not differ from the indication for OLR. Patients with lesions in anterolateral segments are suitable candidates for laparoscopy. Although many types of liver resection are nowadays feasible laparoscopically, major resection and resection of postero-superior segments should be reserved for experienced surgeons with experience in laparoscopic liver resections.

\section{Acknowledgments}

This work was supported by SGS VŠB-TUO Grant No. SP2015/84, SP2015/105, SP2015/146 and SP2015/179 funded by VŠB - Technical University of Ostrava, 17. listopadu 15/2172, 70833 Ostrava-Poruba, Czech Republic, by long term institutional project of University of Ostrava, by European Regional Development Fund in the IT4Innovations Centre of Excellence project (CZ.1.05/1.1.00/02.0070), by MH CZDRO-FNOs/2012 and MH CZ-DRO-FNOs/2013 both funded by University Hospital Ostrava, 17. listopadu 1790, 70852 Ostrava-Poruba, Czech Republic and partially supported by the Science and Research Fund 2014 of the Moravia-Silesian Region, Czech Republic.

\section{Conflict of interest}

The authors declare no conflict of interest.

\section{References}

1. Blumgart LH. Surgery of the liver, biliary tract, and pancreas. Saunders, Elsevier, Philadelphia, US 2007.

2. Hurwitz H, Fehrenbacher L, Novotny W, et al. Bevacizumab plus irinotecan, fluorouracil, and leucovorin for metastatic colorectal cancer. N Engl J Med 2004; 350: 2335-42.

3. El-Gendi AM, Vavra P, Elkayal E, et al. Radiofrequency assisted hepatic resection: a new technique using a bipolar device. J Hepatol 2010; 52: S189.

4. Adam R, Pascal G, Azoulay D, et al. Liver resection for colorectal metastases: the third hepatectomy. Ann Surg 2003; 238: 871-83.

5. El-Gendi AM, Khorsandi SE, Pai M, et al. Repeat hepatic resection using a radiofrequency-assisted technique. Dig Surg 2008; 25: 293-9.

6. Cunningham D, Humblet $\mathrm{Y}$, Siena $\mathrm{S}$, et al. Cetuximab monotherapy and cetuximab plus irinotecan in irinotecan-refractory metastatic colorectal cancer. N Engl I Med 2004; 351: 337-45.

7. Hosmer DW, Lemeshow S, May S. Applied survival analysis: regression modeling of time to event data. Wiley. Hoboken, US 2008.

8. Gagner M, Rheault M, Dubuc J. Laparoscopic partial hepatectomy for liver tumor. Surg Endosc 1993; 6: 99.

9. Frączek M, Sobocki J, Pędziwiatr K, et al. Robotic stereotactic body radiation therapy for liver-limited malignant tumors. Videosurgery Miniinv 2014; 9: 511-6.

10. Dagher I, Proske JM, Carloni A, et al. Laparoscopic liver resection: results for 70 patients. Surg Endosc 2007; 21: 619-24.

11. Topal B, Fieuws S, Aerts R et al. Laparoscopic versus open liver resection of hepatic neoplasms: comparative analysis of shortterm results. Surg Endosc 2008; 22: 2208-13.

12. Mala T, Edwin B, Rosseland AR, et al. Laparoscopic liver resection: experience of 53 procedures at a single center. J Hepatobiliary Pancreat Surg 2005; 12: 298-303. 
13. Bryant R, Laurent A, Tayar C, et al. Laparoscopic liver resection-understanding its role in current practice: the Henri Mondor Hospital experience. Ann Surg 2009; 250: 103-11.

14. Buell JF, Thomas MT, Doty TC, et al. An initial experience and evolution of laparoscopic hepatic resectional surgery. Surgery 2004; 136: 804-11.

15. Buell JF, Thomas MT, Rudich S, et al. Experience with more than 500 minimally invasive hepatic procedures. Ann Surg 2008; 248: 475-86

16. Koffron AJ, Auffenberg G, Kung R, Abecassis M. Evaluation of 300 minimally invasive liver resections at a single institution: less is more. Ann Surg 2007; 246: 385-92.

17. Cho JY, Han HS, Yoon YS, Shin SH. Experiences of laparoscopic liver resection including lesions in the posterosuperior segments of the liver. Surg Endosc 2008; 22: 2344-9.

18. Nguyen KT, Marsh JW, Tsung A, et al. Comparative benefits of laparoscopic vs. open hepatic resection: a critical appraisal. Arch Surg 2011; 146: 348-56.

19. Han HS, Cho JY, Yoon YS. Techniques for performing laparoscopic liver resection in various hepatic locations. J Hepatobiliary Pancreat Surg 2009; 16: 427-32.

20. Vavra P, Ihnat P, Vavrova M, et al. Hand-assisted laparoscopic liver resection using Habib's technique: early experience. Videosurgery Miniinv 2012; 7: 8-12.

21. Zacharoulis D, Khorsandi SE, Vavra P, et al. Pilot study for a new bipolar radiofrequency ablation/aspirator device in the management of primary and secondary liver cancers. Liver Int 2009; 29: 824-30.

22. Buell JF, Cherqui D, Geller DA, et al. The international position on laparoscopic liver surgery: The Louisville Statement, 2008. Ann Surg 2009; 250: 825-30.

23. Koffron A, Geller D, Gamblin TC, Abecassis M. Laparoscopic liver surgery: shifting the management of liver tumors. Hepatology 2006; 44: 1694-700.

24. Cho JY, Han HS, Yoon YS, Shin SH. Feasibility of laparoscopic liver resection for tumors located in the posterosuperior segments of the liver, with a special reference to overcoming current limitations on tumor location. Surgery 2008; 144: 32-8.

25. Cho A, Yamamoto H, Kainuma O, et al. Safe and feasible ex trahepatic Glissonean access in laparoscopic anatomical liver resection. Surg Endosc 2011; 25: 1333-6.

26. Abu Hilal M, Di Fabio F, Teng MJ, et al. Single-centre comparative study of laparoscopic versus open right hepatectomy. J Gastrointest Surg 2011; 15: 818-23.

27. Polignano FM, Quyn AJ, De Figueiredo RS, et al. Laparoscopic versus open liver segmentectomy: prospective, case-matched intention-to-treat analysis of clinical outcomes and cost effectiveness. Surg Endosc 2008; 22: 2564-70.

28. Kaneko H, Takagi S, Otsuka Y, et al. Laparoscopic liver resection of hepatocellular carcinoma. Am J Surg 2005; 189: 190-4.

29. Simillis C, Constantinides VA, Tekkis PP, et al. Laparoscopic versus open hepatic resections for benign and malignant neoplasms: a meta-analysis. Surgery 2007; 141: 203-11.

30. Tranchart H, Di Giuro G, Lainas P, et al. Laparoscopic resection for hepatocellular carcinoma: a matched-pair comparative study. Surg Endosc 2010; 24: 1170-6.
31. Castaing D, Vibert E, Ricca L, et al. Oncologic results of laparoscopic versus open hepatectomy for colorectal liver metastases in two specialized centers. Ann Surg 2009; 250: 849-55.

32. Belli G, Limongelli P, Fantini C, et al. Laparoscopic and open treatment of hepatocellular carcinoma in patients with cirrhosis. Br J Surg 2009; 96: 1041-8.

33. Morino M, Morra I, Rosso E, et al. Laparoscopic vs open hepatic resection: a comparative study. Surg Endosc 2003; 17: 1914-8.

34. Belli G, Fantini C, D’Agostino A, et al. Laparoscopic versus open liver resection for hepatocellular carcinoma in patients with histologically proven cirrhosis: short- and middle-term results. Surg Endosc 2007; 21: 2004-11.

35. Dagher I, Di Giuro G, Dubrez J, et al. Laparoscopic versus open right hepatectomy: a comparative study. Am J Surg 2009; 198: 173-7.

36. Farges $\mathrm{O}$, Jagot P, Kirstetter P, et al. Prospective assessment of the safety and benefit of laparoscopic liver resections. J Hepatobiliary Pancreat Surg 2002; 9: 242-8.

37. Aldrighetti L, Pulitano C, Catena M, et al. A prospective evaluation of laparoscopic versus open left lateral hepatic sectionectomy. J Gastrointest Surg 2008; 12: 457-62.

38. Troisi R, Montalti R, Smeets P, et al. The value of laparoscopic liver surgery for solid benign hepatic tumors. Surg Endosc 2008; 22: 38-44.

39. Lesurtel M, Cherqui D, Laurent A, et al. Laparoscopic versus open left lateral hepatic lobectomy: a case-control study. J Am Coll Surg 2003; 196: 236-42.

40. Rau HG, Buttler E, Meyer G, et al. Laparoscopic liver resection compared with conventional partial hepatectomy: a prospective analysis. Hepatogastroenterology 1998; 45: 2333-8.

41. Mala T, Edwin B, Gladhaug I, et al. A comparative study of the short-term outcome following open and laparoscopic liver resection of colorectal metastases. Surg Endosc 2002; 16: 1059-63.

42. Laurent A, Cherqui D, Lesurtel M, et al. Laparoscopic liver resection for subcapsular hepatocellular carcinoma complicating chronic liver disease. Arch Surg 2003; 138: 763-9.

43. Ito K, Ito H, Are C, et al. Laparoscopic versus open liver resection: a matched-pair case control study. I Gastrointest Surg 2009; 13: 2276-83.

44. Tsinberg M, Teliioglu G, Simpfendorfer CH, et al. Comparison of laparoscopic versus open liver tumor resection: a case-controlled study. Surg Endosc 2009; 23: 847-53.

45. Cai XJ, Yang J, Yu H, et al. Clinical study of laparoscopic versus open hepatectomy for malignant liver tumors. Surg Endosc 2008; 22: 2350-6.

46. Cai XJ, Wang Y, Yu H, et al. Laparoscopic hepatectomy for hepatolithiasis: a feasibility and safety study in 29 patients. Surg Endosc 2007; 21: 1074-8.

47. Lai EC, Tang CM, Ha JP, Li MK. Laparoscopic liver resection for hepatocellular carcinoma: ten-year experience in a single center. Arch Surg 2009; 144: 143-7.

48. Lee KF, Cheung YS, Chong CN, et al. Laparoscopic versus open hepatectomy for liver tumours: a case control study. Hong Kong Med J 2007; 13: 442-8.

49. Shimada M, Hashizume M, Maehara S, et al. Laparoscopic hepatectomy for hepatocellular carcinoma. Surg Endosc 2001; 15: 541-4. 
50. Endo Y, Ohta M, Sasaki A et al. A comparative study of the longterm outcomes after laparoscopy-assisted and open left lateral hepatectomy for hepatocellular carcinoma. Surg Laparosc Endosc Percutan Tech 2009; 19: e171-4.

51. Tang CN, Li MK. Hand-assisted laparoscopic segmentectomy in recurrent pyogenic cholangitis. Surg Endosc 2003; 17: 324-7.

52. Mamada Y, Yoshida H, Taniai N, et al. Usefulness of laparoscopic hepatectomy. J Nippon Med Sch 2007; 4: 158-62.

53. Abu Hilal M, Underwood T, Zuccaro M, et al. Short- and medium-term results of totally laparoscopic resection for colorectal liver metastases. Br I Surg 2010; 97: 927-33.

54. Rowe AJ, Meneghetti AT, Schumacher PA, et al. Perioperative analysis of laparoscopic versus open liver resection. Surg Endosc 2009; 23: 1198-203.

55. O'Rourke N, Shaw I, Nathanson L, et al. Laparoscopic resection of hepatic colorectal metastases. HPB (Oxford) 2004; 6: 230-5.

56. Vigano L, Tayar C, Laurent A, Cherqui D. Laparoscopic liver resection: a systematic review. J Hepatobiliary Pancreat Surg 2009; 16: 410-21.

57. Mizuguchi T, Kawamoto M, Meguro M, et al. Laparoscopic hepatectomy: a systematic review, meta-analysis, and power analysis. Surg Today 2011; 41: 39-47.

58. Sarpel U, Hefti MM, Wisnievsky JP, et al. Outcome for patients treated with laparoscopic versus open resection of hepatocellular carcinoma: case-matched analysis. Ann Surg Oncol 2009; 16: 1572-7.

Received: 2.12.2014, accepted: 22.03.2015. 